\title{
The efficacy and safety of combined administration of intravenous and topical tranexamic acid in primary total knee arthroplasty: a meta-analysis of randomized controlled trials
}

Huazhang Xiong ${ }^{1,2}$, Yi Liu $^{2}$, Yi Zeng ${ }^{1}$, Yuangang $\mathrm{Wu}^{1}$ and Bin Shen ${ }^{1 *}$

\begin{abstract}
Background: The combined administration of intravenous (IV) and topical tranexamic acid (TXA) in primary total knee (TKA) knee remains controversial. The purpose of this meta-analysis was to assess the efficacy and safety of combined administration of IV and topical TXA in primary TKA.

Methods: PubMed, EMBASE, Cochrane Central Register of Controlled Trials, Web of Science, Google Search Engine and China National Knowledge Infrastructure databases were searched for randomized controlled trials (RCTs) were comparing the combined administration of IV and topical TXA following primary TKA. The primary outcomes were total blood loss, maximum hemoglobin drop, and deep venous thrombosis (DVT) and/or pulmonary embolism (PE). The second outcomes were drainage volume and transfusion requirements. Data were analyzed using RevMan 5.3.

Results: A total of 6 RCTs involving 701 patients were included in the meta-analysis. The combined group provided lower total blood loss (MD $-156.34 \mathrm{~mL}, 95 \% \mathrm{Cl},-241.51$ to $-71.18 ; P=0.0003)$, drainage volume $(\mathrm{MD}-43.54 \mathrm{~mL}$, $95 \% \mathrm{Cl}_{1}-67.59$ to $\left.-19.48 ; P=0.0004\right)$, maximum hemoglobin drop $(\mathrm{MD}-0.56 \mathrm{~g} / \mathrm{dl}, 95 \% \mathrm{Cl},-0.93$ to $-0.19 ; P=0.003)$ than IV TXA alone. No significant difference were found in terms of transfusion requirements (RR $0.48,95 \% \mathrm{Cl}$, 0.16 to $1.44 ; P=0.19$ ), DVT (RR 1.01, $95 \% \mathrm{Cl}, 0.14$ to $7.12 ; P=0.99)$ and $\mathrm{PE}(\mathrm{RR} 0.33,95 \% \mathrm{Cl}, 0.01$ to $7.91 ; P=0.49$ ) between the two group. Subgroup analyses shows that the combined group was less total blood loss in nontourniquet $(P=0.0008)$, topical TXA dose $>1.5 \mathrm{~g}(P<0.00001)$ and number of IV TXA $\geq 2$ doses $(P=0.005)$ of TXA compared with the IV group alone.

Conclusions: The available evidence indicates combined group were associated with lower total blood loss, drainage volume, and maximum hemoglobin drop. A similar transfusion requirement was found in both groups. Subgroup analyses demonstrates that total blood loss was less in patients with non-tourniquet, topical TXA dose $>1.5 \mathrm{~g}$ and number of IV TXA $\geq 2$ doses of TXA. There was no increase the rates of DVT and PE.
\end{abstract}

Keywords: Total knee arthroplasty, Tranexamic acid, Intravenous, Topical, Blood loss

\footnotetext{
* Correspondence: shenbin71@hotmail.com

${ }^{1}$ Department of Orthopaedic Surgery, West China Hospital, West China

Medical School, Sichuan University, Chengdu, Sichuan Province 610041,

People's Republic of China

Full list of author information is available at the end of the article
}

(c) The Author(s). 2018 Open Access This article is distributed under the terms of the Creative Commons Attribution 4.0 International License (http://creativecommons.org/licenses/by/4.0/), which permits unrestricted use, distribution, and reproduction in any medium, provided you give appropriate credit to the original author(s) and the source, provide a link to the Creative Commons license, and indicate if changes were made. The Creative Commons Public Domain Dedication waiver (http://creativecommons.org/publicdomain/zero/1.0/) applies to the data made available in this article, unless otherwise stated. 


\section{Background}

Total knee arthroplasty (TKA) and total hip arthroplasty (THA) is an effective orthopedic procedure for patients with severe knee and hip diseases [1-4]. However, significant blood loss may occur due to hyper-fibrinolysis induced by surgical trauma or tourniquet. Thus, it often leads to significant postoperative anemia and transfusion requirements $[5,6]$. Postoperative anemia may be an important issue associated with adverse events, including increased mortality and morbidity and prolonged hospitalization due to transfusion-related needs.

Tranexamic acid (TXA) is a synthetic lysine analog, it can competitively inhibit the activation of plasminogen and plasmin binding protein $[7,8]$. Several randomized controlled trials (RCTs) $[9,10]$ and meta-analysis studies $[11,12]$ have shown that intravenous (IV) $[13,14]$, topical (TA) [8] or oral [15] application of TXA can successfully reduce blood loss and transfusions in primary TKA without increasing the risk of thrombosis. Recently, an increasing number of studies have focused on the issue that when compared with only IV or TA TXA, whether combination application of IV and topical TXA has additional benefits in primary TKA $[16,17]$. Compared with IV TXA, TA application has the advantage of being easy to administer, it leads to $70 \%$ lower systemic absorption and thus may be a safer alternative to giving it systemically. Additionally, topical application of TXA has the advantage of inducing partial microvascular hemostasis by stopping fibrin clot dissolution in the affected area $[4,8,11,18]$. Once topically applied, TXA is rapidly absorbed and achieves the effect of hemostasis.

Several meta-analyses [19-21] were performed to evaluate the combination of IV and topical TXA in primary TKA. However, it may have some limitations and the conclusion might have the bias: First, as they included both TKA and THA in the analysis [19, 20], they did not account for the difference in the type of surgery. It cannot draw meaningful conclusions, and we believed that stricter criteria need to be applied to determine the benefits of combining TXA in a meta-analysis. Second, these studies were also affected by many other confounding factors [19-21], such as the application of tourniquet or non-tourniquet, and different topical TXA dose or the number of IV TXA. Thus, subgroup analysis based on the application of tourniquet or non-tourniquet, and topical TXA dose $(\leq 1.5 \mathrm{~g}$ or $>1.5 \mathrm{~g})$ or the number of IV TXA (single or $\geq 2$ doses) were conducted, resulting in more accurate conclusions. Therefore, because of this bias factor, the efficacy of the combined IV and topical TXA in primary TKA has not been clearly concluded. Currently, there have been some well-designed studies [21-24] comparing the efficacy of combined administration of IV and topical TXA versus IV-TXA alone during TKA. Thus, the authors performed a meta-analysis to assess the highest evidence-based (level I) studies in order to investigate the effectiveness and safety of combined IV and TA application of TXA versus single IV TXA after primary TKA in regarding with (1) blood loss, including total blood loss and drainage volume; (2) transfusion requirements and maximum hemoglobin drop; and (3) thromboembolic complications, including deep venous thrombosis (DVT) and/or pulmonary embolism (PE). Additionally, subgroup analyses were also conducted to evaluate the benefits of the application of tourniquet or non-tourniquet, different topical $(\leq 1.5 \mathrm{~g}$ or $>1.5 \mathrm{~g}$ ) or the number of IV TXA (single or $\geq 2$ doses) for total blood loss, maximum hemoglobin drop and transfusion requirements.

\section{Methods}

The method used for this meta-analysis is based on the recommended PRISMA checklist guidelines [25]. The study was registered in the Research Registration Unique Identifying Number (review registry 249; http:// www.researchregistry.com).

\section{Search strategy}

We searched the following electronic databases: PubMed (1966 to December 2017), Embase (1974 to December 2017), Cochrane Central Register of Controlled Trials (December 2017) and Web of Science (1990 to December 2017). To identify additional potential studies, we also used the Google Search Engine (December 2017) and China National Knowledge Infrastructure (December 2017). We used the following keywords to search the database above: (total knee arthroplasty OR total knee replacement OR TKA OR TKR) AND (Tranexamic acid OR TXA OR TA). A search strategy with "PubMed" as an example in a manuscript: \#1 Total Knee Arthroplasty; \#2 Total Knee Replacement; \#3 TKA; \#4 TKR; \#5 \#1 OR \#2 OR \#3 OR \#4; \#6 Tranexamic Acid; \#7 TXA; \#8 TA; \#9 \#6 OR \#7 OR \#8; \#10 \#5 AND \#9. There is no restriction on language and region.

\section{Inclusion criteria}

The inclusion criteria for these studies were performed as follows: (1) studies were RCTs that included combined IV and topical application of TXA, and IV application of TXA; (2) patients were performed primary unilateral TKA; and (3) The outcomes of each RCTs included at least one of the following: blood loss, drainage volume, transfusion requirements, maximum hemoglobin drop, DVT, and PE. The studies were excluded if: (1) there were no sufficient outcomes; (2) revision or simultaneous bilateral total knee arthroplasty. All titles and abstracts were independently reviewed by two reviewers (XXX, XXX) to identify potential studies. These eligible studies were then obtained for inclusion 
based on the review of the full text. The differences were resolved by consensus after discussion, or a third reviewer was consulted if necessary.

\section{Assessment of methodological quality}

Two reviewers (XXX, XXX) assessed independently the methodological quality as described by the Cochrane Collaboration for Systematic Reviews [26]. The six items included random sequence generation, allocation sequence concealment, blinding, incomplete outcome data, selective outcome reporting, and other risks. The overall methodological quality of each included study was characterized as low (low risk of bias), high (high risk of bias), and unclear (unclear risk of bias). Additionally, the two reviewers (XXX, XXX) used the modified Jadad scale to assess the risk of bias of the included studies [27]. Studies obtaining 4 or more points (up to 8 points) is considered to be of high quality, and the differences will be resolved by consensus after discussion, and if necessary, the third reviewer was consulted (XXX).

\section{Outcome measures}

The effectiveness and safety of combined IV and TA application of TXA versus single IV TXA after primary TKA in this meta-analysis were compared. The primary outcomes were total blood loss, maximum hemoglobin drop, and deep venous thrombosis (DVT) and/or pulmonary embolism (PE). The second outcomes were drainage volume and transfusion requirements. Furthermore, Subgroup analysis was also performed based on whether the use of tourniquet and drainage tube to compare the additional benefits for blood loss.

\section{Data extraction}

Two reviewers (XXX, XXX) independently extracted outcomes from the included studies. Their data includes authors, publication year, patients, age, and the intervention method of TXA, the method of DVT prophylaxis and screening, blood transfusion criterion. If the study reported the same patient during the different follow-up period, we chose a longer follow-up time to avoid duplication of data.

\section{Data synthesis}

Statistical analyses of the meta-analysis were performed using RevMan 5 software (Version 5.3, the Cochrane Collaboration, UK). For continuous data, the mean differences (MD) and 95\% confidence interval (CI) were calculated, such as total blood loss, drainage volume, and maximum hemoglobin drop. For dichotomous data, the risk ratio (RR) and 95\% confidence interval (CI) were calculated, such as transfusion requirements, DVT or PE. The chi-squared test and I2 statistic were used to assess statistical heterogeneity. If the chi-squared test $>0.1$ or the $\mathrm{I}^{2}<50 \%$, the fixed-effects model was chosen. Otherwise, a random-effects model was chosen. Publication bias was tested independently using funnel plots of total blood loss, drainage volume, maximum hemoglobin drop, transfusion requirements and DVT. If the funnel plot was symmetric, then there was a low potential for publication bias, or vice-versa.

\section{Results}

\section{Search results}

The flow chart in Fig. 1 shows the process by screening the potential studies. A total of 1689 studies were screened through the initial search, 1410 were excluded on the basis of their titles and abstracts, and then leaving 279 were read for full-text. After scanning full-text, 273 were also excluded since it did not meet inclusion criteria. Thus, 6 RCTs had been published between 2014 and 2017 used in the meta-analysis [16, 17, 22-24, 28]. These studies included 351 patients in combined administration of IV and topical TXA group (combined group) and 350patients in IV TXA group (IV TXA group). Sample size in included trials ranged from 25 to 95 . Of all 6 studies, 5 studies were published in the English language $[16,17,22-24], 1$ study was published in the Chinese language [28]. Randomization was conducted in all 6 studies [16, 17, 22-24, 28]. All but 1 study [28] reported randomization method, of which 4 studies [17, 22-24] were reported using a computer-generated randomization, and in 1 [16] study reported the use of sealed envelope technique. There were 4 studies $[16,17$, $22,24]$ performed a clear blinding. All but two studies [17, 22] performed drainage, and the tourniquet was applied in four studies [16, 17, 23, 24]. All patients in the included studies received DVT prophylaxis of physical and chemical methods, including intermittent pneumatic compression, low-molecular-weight heparin, aspirin or rivaroxaban. Table 1 summarizes the baseline characteristics of included studies.

Table 2 summarizes the methodological quality and the risk of bias of the included studies. All 6 trials were relatively well designed, and the modified Jadad scores showed that the quality of the 6 trials was high, of which there were 2 at least 4 points, there were 3 up to 7 points. The meta-analysis used independently funnel plots of total blood loss, drainage volume, maximum hemoglobin drop, transfusion requirements and DVT to assess publication bias; the plots were generally symmetrical and shown a lower publication bias (Fig. 2 A, B, C, D, E).

\section{Meta-analysis of blood loss}

A total of five studies [16, 17, 22-24] report relevant data regarding total blood loss (326 and 325 patients in the combined group and IV group, respectively). The outcome of meta-analysis indicates that total blood loss 


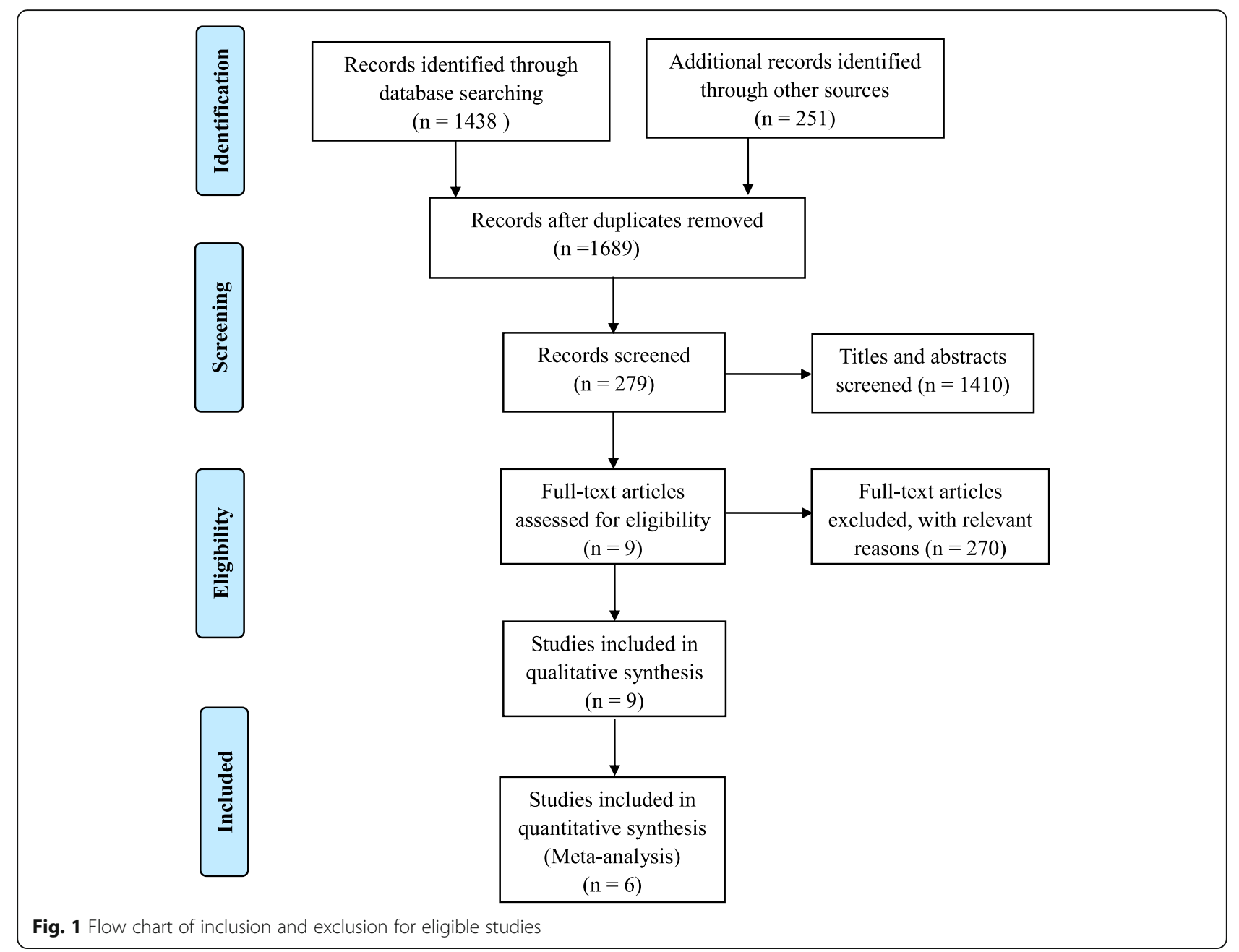

found in the combined group significantly reduced blood loss by a mean of $156.34 \mathrm{~mL}$ compared with the IV group (95\% CI, -241.51 to $-71.18 ; P=0.0003$ ) (Fig. 3). A random-effects model was used since there was significant heterogeneity among the studies $(P=$ $0.002, \mathrm{I}^{2}=77 \%$ ).

Subgroup analysis was performed base on the use of tourniquet or non-tourniquet, different topical $(\leq 1.5 \mathrm{~g}$ or $>1.5 \mathrm{~g}$ ) or number of IV TXA (single or $\geq 2$ doses) of TXA. The outcome revealed that there was the significant difference between the two groups in terms of tourniquet or non-tourniquet, topical TXA dose or the number of IV TXA (Table 3).

\subsection{Meta-analysis of drainage volume}

A total of three studies [16, 24, 28] reported relevant data regarding drainage volume (167 and 167 patients in the combined group and IV group, respectively). The outcome of meta-analysis indicates that drainage volume found in the combined group significantly reduced drainage volume by a mean of $43.54 \mathrm{~mL}$ compared with the IV group (95\% CI, -67.59 to 19.48; $P=0.0004$ ) (Fig. 4). A fixed model was used since there was no significant heterogeneity among the studies $\left(P=0.34, \mathrm{I}^{2}=7 \%\right)$.

\section{Meta-analysis of maximum hemoglobin drop}

A total of four studies [16, 17, 23, 24] reported relevant data regarding maximum hemoglobin drop (296 and 295 patients in the combined group and IV group, respectively). The outcome of meta-analysis indicates that maximum hemoglobin drop found in the combined group significantly reduced maximum hemoglobin drop by a mean of $0.56 \mathrm{~g} / \mathrm{dl}$ compared with the IV group ( $95 \% \mathrm{CI},-0.93$ to $-0.19 ; P=0.003$ ) (Fig. 5). A random-effects model was used since there was significant heterogeneity among the studies $(P$ $\left.<0.00001, \mathrm{I}^{2}=90 \%\right)$. Similar results were received in subgroup analysis based on the application of tourniquet or non-tourniquet, topical TXA dose or the number of IV TXA (Table 4). 


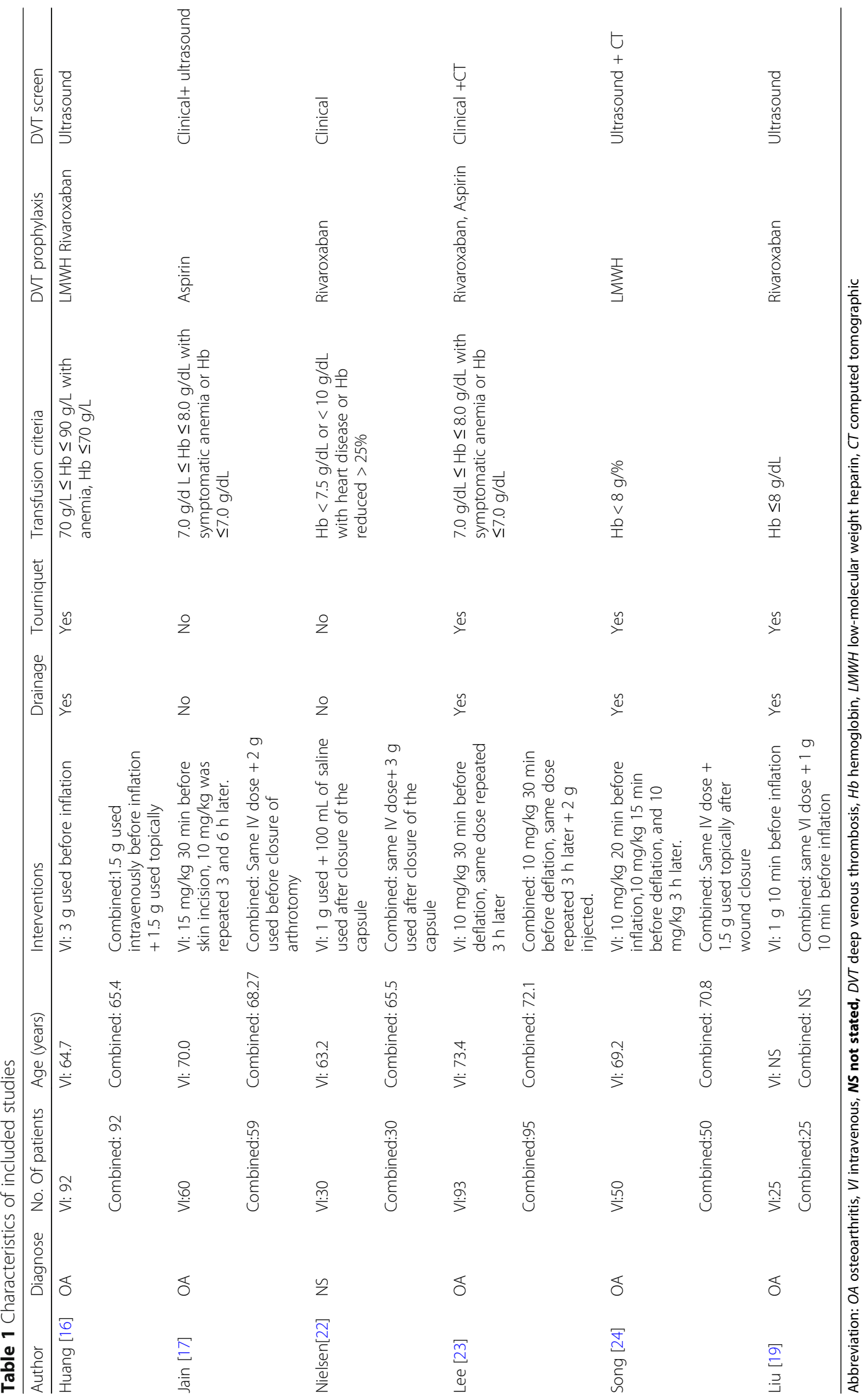


Table 2 Quality assessment and modified Jadad score of included 6 randomized controlled trials

\begin{tabular}{|c|c|c|c|c|c|c|c|}
\hline Studies (years) & $\begin{array}{l}\text { Random sequence } \\
\text { generation }\end{array}$ & $\begin{array}{l}\text { Allocation } \\
\text { concealment }\end{array}$ & Blinding & $\begin{array}{l}\text { Incomplete } \\
\text { outcome data }\end{array}$ & $\begin{array}{l}\text { Selective } \\
\text { reporting }\end{array}$ & Other bias & $\begin{array}{l}\text { Modified Jadad } \\
\text { score }\end{array}$ \\
\hline Huang (2014) [16] & Low & Low & Low & Low & Low & Low & 8 \\
\hline Liu (2015) [19] & Unclear & Unclear & Unclear & Low & Low & Low & 4 \\
\hline Jain (2016) [17] & Low & Low & Low & Low & Low & Low & 7 \\
\hline Nielsen (2016) [22] & Low & Low & Low & Low & Low & Low & 8 \\
\hline Lee (2017) [23] & Low & Low & Unclear & Low & Low & Low & 6 \\
\hline Song (2017) [24] & Low & Low & Low & Low & Low & Low & 7 \\
\hline
\end{tabular}

Abbreviation: Low:low risk of bias; Unclear: unclear risk of bias; High: high risk of bias

\section{Meta-analysis of transfusion requirements}

A total of five studies [16, 17, 22-24] reported relevant data regarding transfusion requirements (326 and 325 patients in the combined group and IV group, respectively). The outcome of meta-analysis indicates that transfusion requirements found 4 of 326 patients in the combined group, compared to 9 of 325 patients in the IV group. The risk ratio (RR) shown there was no significant difference between the two group in the incidence of transfusion requirement $(R R=0.48,95 \% \mathrm{CI}, 0.16$ to
$1.44 ; P=0.19$ ) (Fig. 6). A Fixed-effects model was used since there was no significant heterogeneity among the studies $\left(P=0.69, \mathrm{I}^{2}=0 \%\right)$. Similar results were received from subgroup analysis based on the application of the tourniquet or non-tourniquet, topical dose and number of IV TXA (Table 4).

\section{Meta-analysis of DVT and PE}

A total of six studies [16, 17, 22-24, 28] reported relevant data regarding DVT (351 and 350 patients in the
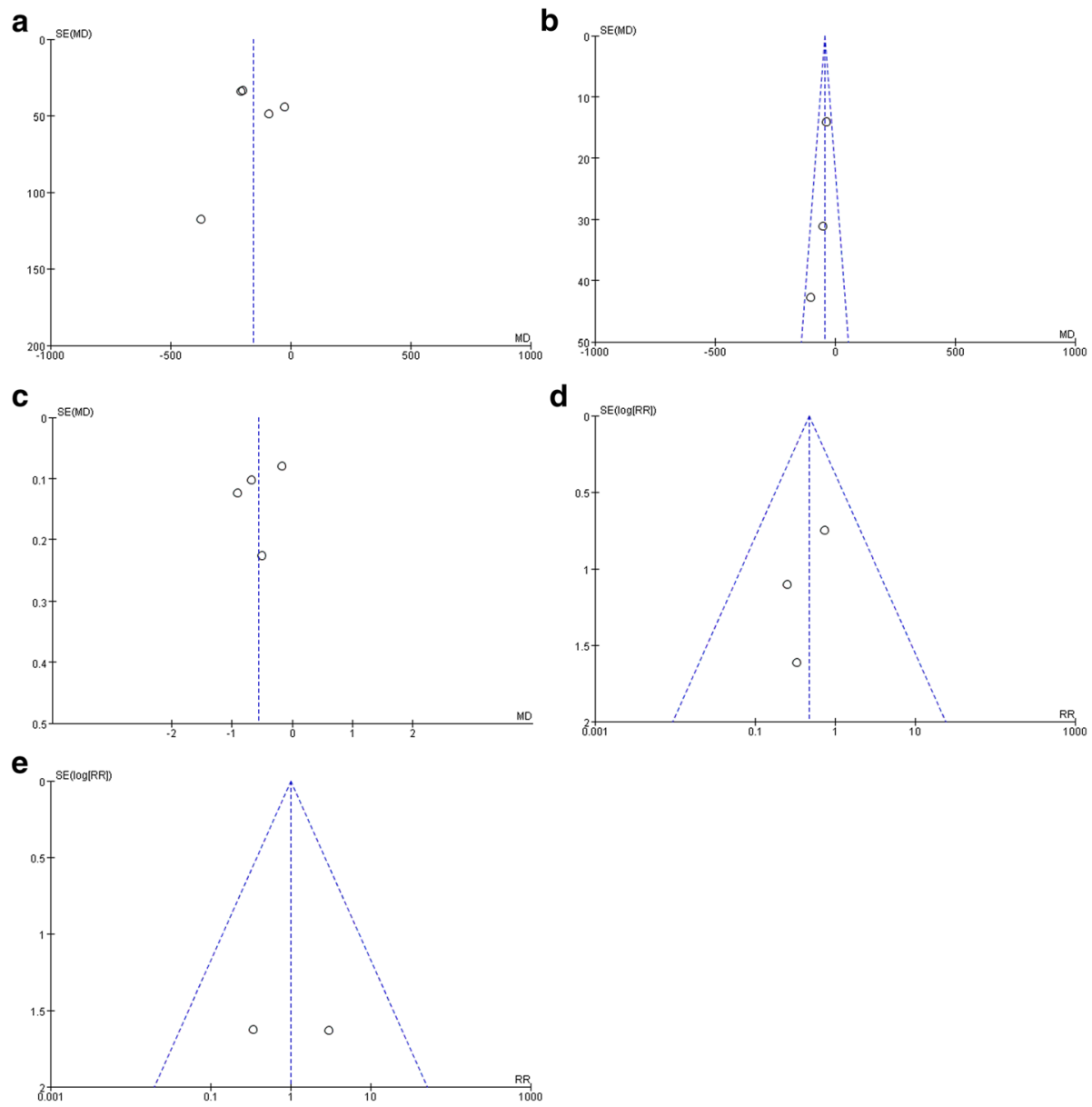

Fig. 2 Funnel plot of total blood loss (a), drainage volume (b), maximum hemoglobin drop (c), transfusion requirements (d), and DVT (e) 


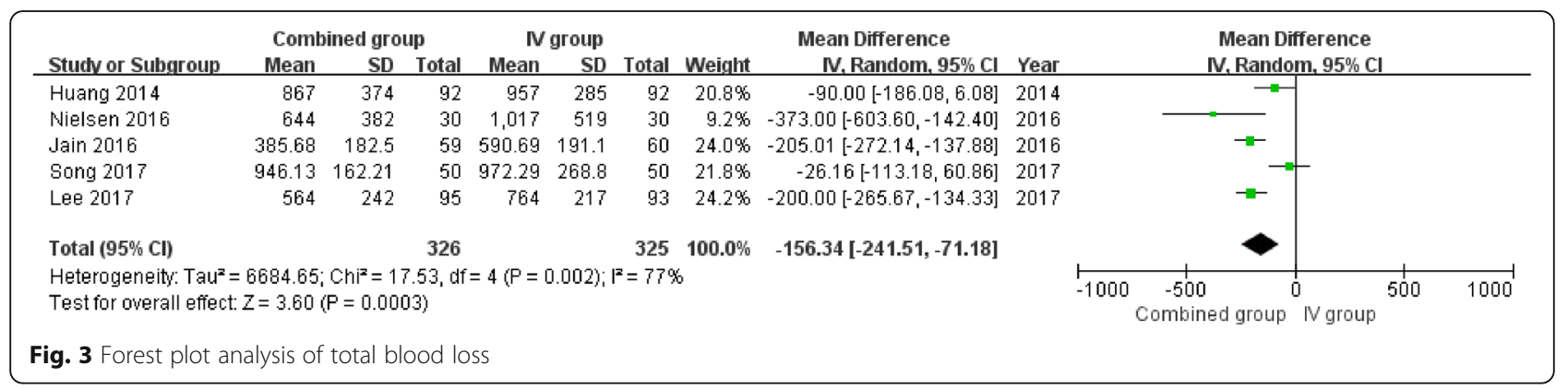

combined group and IV group, respectively). There was 1 in each of the two groups. Of which, 1 of 92 patients [16] who received combination intravenous and topical TXA developed DVT, and 1 of 60 patients [17] who received only intravenous TXA developed DVT (RR 1.01, $95 \% \mathrm{CI}, 0.14$ to $7.12 ; P=0.99$ ) (Fig. 7). All but 1 study [23] reported 1 PE found in the IVTXA (RR 0.33,95\% CI, 0.01 to $7.91 ; P=0.49$ ). Thus, no significant differences were found in the two groups in terms of the incidence of DVT and PE. A fixed-effects model was used, since there was no significant heterogeneity among the studies $\left(P=0.34, \mathrm{I}^{2}=0 \%\right)$.

\section{Discussion}

Tranexamic acid, an analog of the amino acid lysine, successfully reduces perioperative blood loss and transfusion requirements in primary TKA $[5,6,29,30]$. TXA can be applied during the perioperative period either intravenously $[13,31]$, topically $[8,32]$, and orally $[15,33]$. Recently, an increasing number of studies have focused on the issue that when compared with only intravenous or topical TXA, whether combination application of IV and topical TXA has additional benefits in primary TKA $[16,17,22]$. Thus, we performed the meta-analysis to assess the efficacy and safety of combined application versus intravenous application of TXA in TKA.

The main finding of this meta-analysis is that the combined application intravenous and topical of TXA can significantly reduce postoperative total blood loss, drainage volume, maximum hemoglobin drop compared to the application of intravenous TXA alone. Subgroup analyses showed that total blood loss was less in patients with non-tourniquet, topical TXA dose $>1.5 \mathrm{~g}$ and IV TXA $\geq 2$ doses. No significant differences were found in the incidence of DVT and PE between the two groups.

The administration of IV TXA in TKA has been well established in a lot of literature. Akgül et al. [34] reported $20 \mathrm{mg} / \mathrm{kg}$ IV-TXA given before the skin incision in the primary TKA could decrease the total blood loss from $1166.42 \mathrm{~mL}$ to $634.03 \mathrm{~mL}$ and reduce the drainage volume from $640.74 \mathrm{~mL}$ to $311.11 \mathrm{~mL}$. Pitta et al. [35] performed another retrospective study involving 610 patients during 4 years, they reported the administered IV of TXA resulted in a significant decrease by $9.4 \%$ in blood loss compared to the control group in TKA, and no significantly different was found in the incidence of DVT. Compared with the safety concerns with intravenous administration, topical TXA has been a growing interest to prevent bleeding. As previously reported, it was considered to less of $70 \%$ systemic absorption and thus may be a systemic alternative. Ishida et al. [36] conducted a randomized controlled trial that injected $2000 \mathrm{mg} /$ $20 \mathrm{~mL}$ topical TXA compared with a placebo group in TKA, the results revealed that postoperative decreasing in $\mathrm{Hb}$ level and knee joint swelling was significantly reduced in the TXA group compared to the control group. Recently, a new strategy of combined administration of TXA was explored considering the advantages of both methods. A randomized, double-blind, placebo-controlled trial [22] of 60 patients comparing patients who received combined IV and topical TXA or IV TXA in primary TKA found that combined administration results in significantly lower total blood loss and postoperative $\mathrm{Hb}$ level, while the incidence of DVT was similar between the two groups. Lee et al. [23] have also found the similar results that while there were no patients in any study group received an allogeneic transfusion, the combined group had lower total blood loss than the IV-only group.

The current meta-analysis shows that combined group could effectively reduce postoperative total blood loss by about $156.34 \mathrm{~mL}$ compared with IV TXA alone. Similarly, subgroup analysis suggested that there is also the significant difference between the two group in terms of the use of tourniquet or non-tourniquet, topical $(\leq 1.5 \mathrm{~g}$ or $>1.5 \mathrm{~g}$ ) and the number of IV TXA (single or $\geq 2$ doses). Furthermore, the meta-analysis indicates that drainage volume found in the combined group significantly reduced drainage volume by a mean of $43.54 \mathrm{~mL}$ compared with the IV group. Thus, the combined 
Table 3 Results of meta-analysis and subgroup analyses of the included studies

\begin{tabular}{|c|c|c|c|c|c|c|}
\hline \multirow{2}{*}{$\begin{array}{l}\text { Results (Combined } \\
\text { vs. IV groups) }\end{array}$} & \multirow{2}{*}{$\begin{array}{l}\text { No.of } \\
\text { studies } \\
\text { / knee }\end{array}$} & \multirow[t]{2}{*}{$P$} & \multicolumn{3}{|c|}{ Effect Size } & \multirow[b]{2}{*}{ Model } \\
\hline & & & $\overline{\mathrm{MD} / \mathrm{RR}}$ & $95 \% \mathrm{Cl}$ & $\begin{array}{l}\text { Heterogeneity } \\
\mathrm{p}\left(\mathrm{I}^{2}\right)\end{array}$ & \\
\hline \multicolumn{7}{|l|}{ 1. Total blood loss } \\
\hline All studies & $5 / 651$ & 0.0003 & -156.34 & 241.51 to -71.18 & $0.002(77 \%)$ & Random \\
\hline \multicolumn{7}{|c|}{ Tourniquet or Non-tourniquet } \\
\hline Tourniquet & $3 / 471$ & 0.05 & -108.68 & -217.44 to 0.08 & $0.005(81 \%)$ & Random \\
\hline Non-tourniquet & $2 / 179$ & 0.0008 & -251.30 & -398.40 to -104.19 & $0.17(47 \%)$ & Fixed \\
\hline \multicolumn{7}{|l|}{ Topical TXA dose } \\
\hline$\leq 1.5 \mathrm{~g}$ & $2 / 284$ & 0.10 & -54.93 & -119.43 to 9.57 & $0.33(0 \%)$ & Fixed \\
\hline$>1.5 \mathrm{~g}$ & $3 / 367$ & $<0.00001$ & -209.39 & -255.95 to -162.83 & $0.36(1 \%)$ & Fixed \\
\hline \multicolumn{7}{|l|}{ Number of IV TXA } \\
\hline Single dose & $2 / 244$ & 0.13 & -210.91 & -485.30 to 63.47 & $0.03(80 \%)$ & Random \\
\hline$\geq 2$ doses & $3 / 407$ & 0.005 & -147.43 & -251.16 to -43.69 & $0.002(84 \%)$ & Random \\
\hline \multicolumn{7}{|c|}{ 2. Maximum hemoglobin drop } \\
\hline All studies & $4 / 591$ & 0.003 & -0.56 & -0.93 to -0.19 & $<0.00001(90 \%)$ & Random \\
\hline \multicolumn{7}{|c|}{ Tourniquet or Non-tourniquet } \\
\hline Tourniquet & $3 / 472$ & 0.05 & -0.52 & -1.04 to 0.00 & $<0.00001(92 \%)$ & Random \\
\hline Non-tourniquet & $1 / 119$ & $<0.00001$ & -0.68 & -0.88 to -0.48 & - & - \\
\hline \multicolumn{7}{|l|}{ Topical TXA dose } \\
\hline$\leq 1.5 \mathrm{~g}$ & $2 / 284$ & 0.006 & -0.21 & -0.35 to -0.06 & $0.17(47 \%)$ & Fixed \\
\hline$>1.5 \mathrm{~g}$ & $2 / 307$ & $<0.00001$ & -0.78 & -0.99 to -0.56 & $0.17(47 \%)$ & Fixed \\
\hline \multicolumn{7}{|l|}{ Number of IV TXA } \\
\hline Single dose & $1 / 184$ & 0.03 & -0.17 & -0.33 to -0.01 & - & - \\
\hline$\geq 2$ doses & $3 / 407$ & $<0.00001$ & -0.73 & -0.93 to -0.54 & $0.21(36 \%)$ & Fixed \\
\hline \multicolumn{7}{|c|}{ 3. Transfusion requirements } \\
\hline All studies & $5 / 651$ & 0.19 & 0.48 & 0.16 to 1.44 & $0.69(0 \%)$ & Fixed \\
\hline \multicolumn{7}{|c|}{ Tourniquet or Non-tourniquet } \\
\hline Tourniquet & $3 / 472$ & 0.70 & 0.75 & 0.17 to 3.26 & - & - \\
\hline Non-tourniquet & $2 / 179$ & 0.16 & 0.28 & 0.05 to 1.64 & $0.89(0 \%)$ & Fixed \\
\hline \multicolumn{7}{|l|}{ Topical TXA dose } \\
\hline$\leq 1.5 \mathrm{~g}$ & $3 / 344$ & 0.50 & 0.64 & 0.17 to 2.37 & $0.65(0 \%)$ & Fixed \\
\hline$>1.5 \mathrm{~g}$ & $2 / 307$ & 0.21 & 0.25 & 0.03 to 2.21 & - & - \\
\hline \multicolumn{7}{|l|}{ Number of IV TXA } \\
\hline Single dose & $2 / 244$ & 0.50 & 0.64 & 0.17 to 2.37 & $0.65(0 \%)$ & \\
\hline$\geq 2$ doses & $3 / 407$ & 0.21 & 0.25 & 0.03 to 2.21 & - & - \\
\hline 4. Drainage volume & $3 / 334$ & 0.0004 & -43.54 & -67.59 to -19.48 & $0.34(7 \%)$ & Fixed \\
\hline 5. DVT & $6 / 701$ & 0.99 & 1.01 & 0.14 to 7.12 & $0.34(0 \%)$ & Fixed \\
\hline
\end{tabular}

Abbreviation: RR, risk ratio; MDs, mean differences; IV, Intravenous; DVT, deep venous thrombosis

administration of TXA could be a reasonable alternative to IV TXA alone for decreasing blood loss and drainage volume in primary TKA.

In our meta-analysis, the rate of transfusion requirements was slightly less for the combined group (1.2\%) than for the IV TXA group (2.8\%), but the difference was not statistically significant (RR $0.48, P=$
0.19). Subgroup analyses showed similar results for the tourniquet or non-tourniquet and different topical or the number of IV TXA. Huang et al. [16] performed one RCT, $1.5 \mathrm{~g}$ topical TXA administered combined with $1.5 \mathrm{~g}$ IV-TXA, and there was no statistically significant difference regarding transfusion requirements between the two groups. Another RCT 


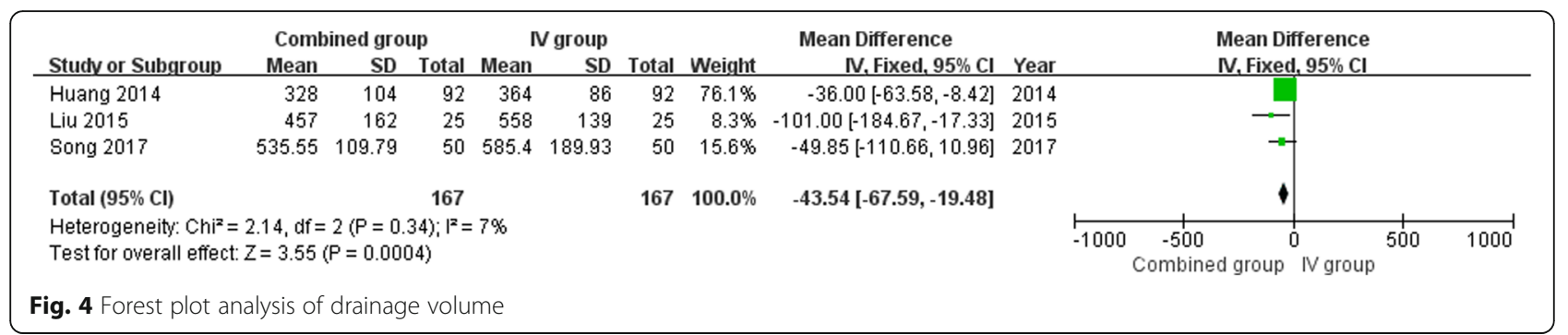

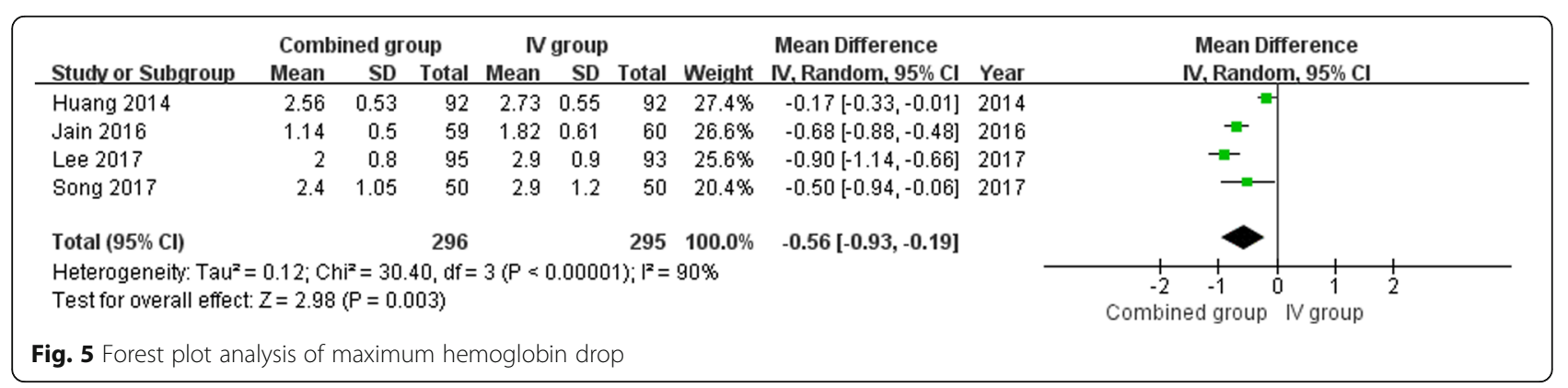

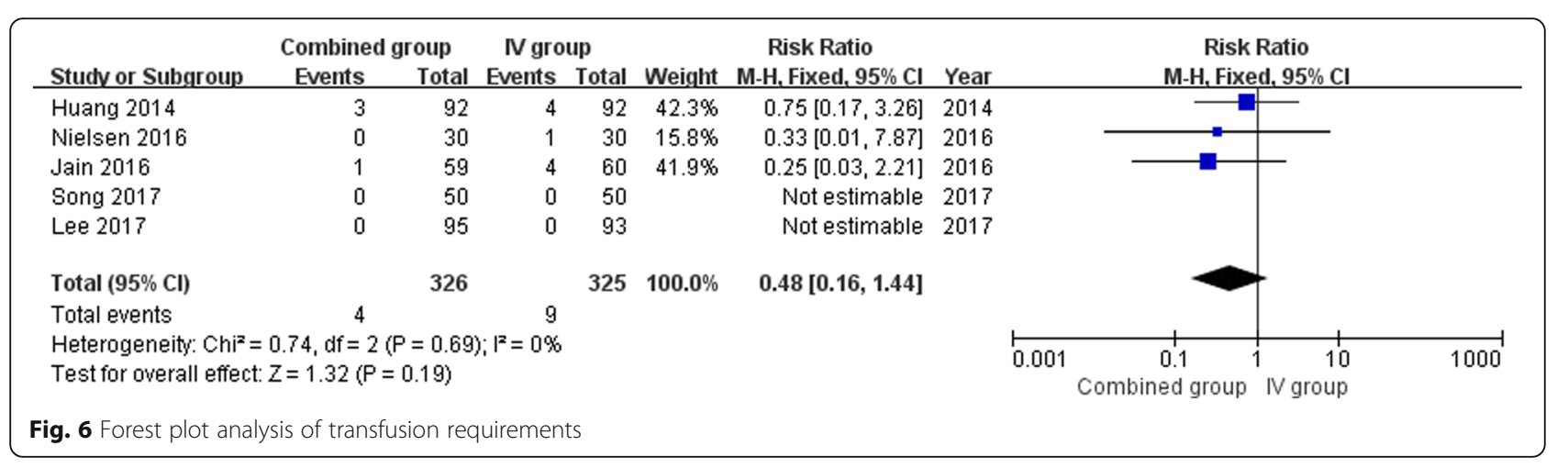

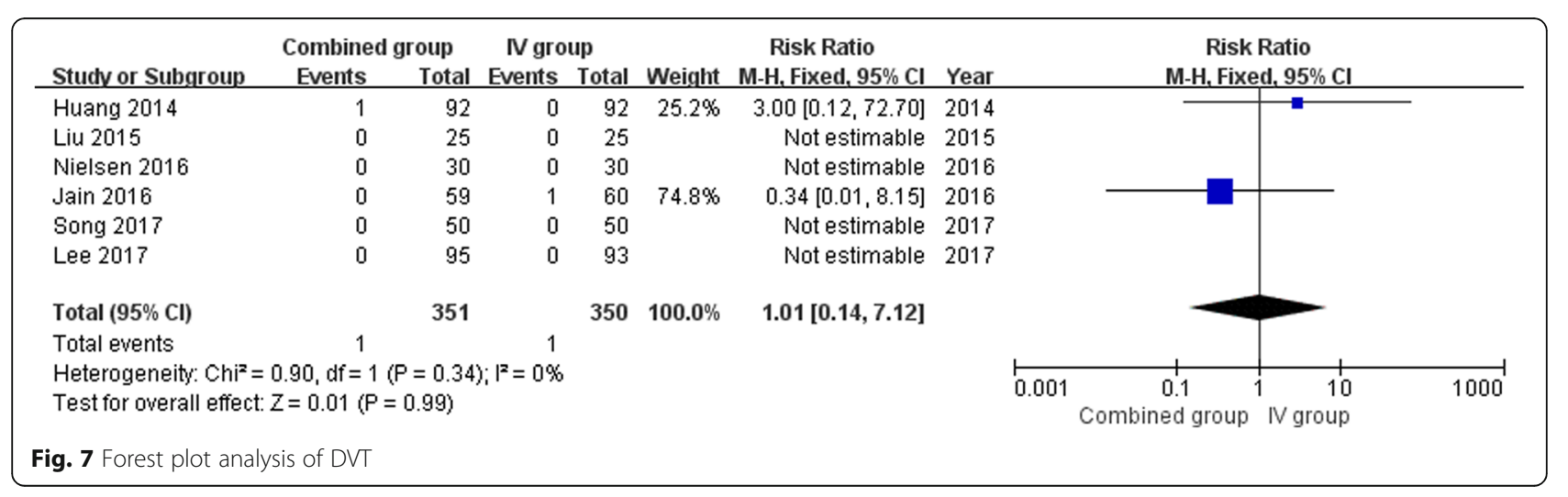


[23], 119 patients were randomized into combined group and IV group alone, the combined group provided better results than IV alone in total blood loss $(590.69 \pm$ $191.1 \mathrm{mLvs}$. $385.68 \pm 182.5 \mathrm{~mL}, P<0.001)$, but no difference in blood transfusion rate $(6.6 \%$ vs. $1.6 \%, P=0.364)$. The result of our meta-analysis evaluating transfusion rates was consistent with these studies.

Thromboembolic prophylaxis methods were performed in all of the studies and as follow: low-molecular-weight heparin, aspirin, and enoxaparin. As Anderson et al. [37] reported in "N Engl J Med", they found that among patients who received 5 days of rivaroxaban prophylaxis following TKA/THA, extended prophylaxis with aspirin was not significantly different from rivaroxaban in the prevention of DVT. Additionally, all thromboembolic events were detected by clinical symptomatic, routine Doppler ultrasound, or CT angiography. Finally, there was 1 in each of the two groups. The total rate of DVT was $0.03 \%$. There was no difference in both two group $(P=0.99) .1$ PE was found in the IV TXA group. Our findings are consistent with those of RCT $[17,23]$ or meta-analysis [38, 39] which found that no previous studies have reported increased rates of symptomatic DVT or PE with the combined administration of TXA in TKA.

The current study had the following strengths. First, all of the included studies have been well-designed and satisfied the defined eligibility criteria comparing the efficacy of combined TXA versus intravenous administration of TXA during TKA. Second, subgroup analysis was performed based on the use of the tourniquet or non-tourniquet and different topical or the number of IV TXA. The results showed that combined administration of TXA in TKA can effectively reduce total blood loss and maximum hemoglobin drop compared with IV TXA alone. Third, this study independently used funnel plots to assess publication bias, the plots were generally symmetrical and shown a lower publication bias. However, the meta-analysis also has limitations. First, the reported blood loss methods are not consistent, which may lead to deviations in the clinical outcome of blood loss. In addition, the method for estimating displacement is not detailed, so it cannot exclude the result deviation caused by human factors measurement. Second, the number of RCTs included was limited. Thus, more carefully and scientifically designed RCTs are needed in the future to further confirm and compare the different results. Third, due to the limited sample size of the study, our meta-analysis failed to extract adequate data pertaining to some items from these studies, such as function outcomes, patient satisfaction, and other complications, etc. Last, there was substantial heterogeneity in the meta-analysis of several outcomes, including total blood loss and drainage volume. However, taking into account the effects of the tourniquet and different topical TXA dose $(\leq 1.5 \mathrm{~g}$ or $>1.5 \mathrm{~g})$ or number of IV TXA (single or $\geq 2$ doses), thus subgroup analysis was performed to decrease heterogeneity.

\section{Conclusions}

This meta-analysis of currently available evidence indicates that combined administration of intravenous and topical TXA in primary TKA can significantly reduce total blood loss, drainage volume and maximum hemoglobin drop compared with IV TXA alone. The main finding, however, is that there is no significant difference in transfusion rates because this is the most clinically relevant point in this meta-analysis.

\section{Abbreviations \\ Cl: Confidence interval; DVT: DVT; IV: Intravenous; MD: Mean differences; PE: Pulmonary embolism; RCT: Randomized controlled trials; RR: Risk ratio; SD: Standard deviation; TA: Tranexamic acid; TKA: Total knee arthroplasty; TKR: Total knee replacement; TXA: Tranexamic acid}

\section{Availability of data and materials}

All data and materials are contained within the manuscript.

\section{Authors' contributions}

Bin Shen conceived, designed and coordinated the experiments and drafted the manuscript. Huazhang Xiong and Yi Zeng contributed to data

acquisition. Yi Zeng and Yuangang Wu analysed and interpreted the data. Huazhang Xiong and Bin Shen revised the manuscript. All authors read and approved the final manuscript.

\section{Ethics approval and consent to participate}

Ethical approval is not necessary because it is a comment on previously published articles and does not involve the handling of any personal patient data.

\section{Consent for publication}

All authors agree to publish.

\section{Competing interests}

The authors declare that they have no competing interests.

\section{Publisher's Note}

Springer Nature remains neutral with regard to jurisdictional claims in published maps and institutional affiliations.

\section{Author details}

${ }^{1}$ Department of Orthopaedic Surgery, West China Hospital, West China Medical School, Sichuan University, Chengdu, Sichuan Province 610041, People's Republic of China. '2Department of Orthopedic Surgery, The First Affiliated Hospital of Zunyi Medical College, Zunyi 563003, Guizhou Province, China.

Received: 23 February 2018 Accepted: 10 July 2018

Published online: 07 September 2018

\section{References}

1. Zeni JA Jr, Axe MJ, Snyder-Mackler L. Clinical predictors of elective total joint replacement in persons with end-stage knee osteoarthritis. BMC Musculoskelet Disord. 2010;11:86

2. Levine BR, Haughom B, Strong B, Hellman M, Frank RM. Blood management strategies for total knee arthroplasty. J Am Acad Orthop Surg. 2014;22:361-71.

3. Edelstein Al, Kwasny MJ, Suleiman LI, Khakhkhar RH, Moore MA, Beal MD, et al. Can the American College of Surgeons risk calculator predict 30-day complications after knee and hip arthroplasty? J Arthroplast 2015;30:5-10.

4. Wong J, Abrishami A, El Beheiry H, Mahomed NN, Roderick Davey J, Gandh $R$, et al. Topical application of tranexamic acid reduces postoperative blood loss in total knee arthroplasty: a randomized, controlled trial.J Bone Joint Surg Am $2010 ; 92: 2503-2513$. 
5. Chen JY, Chin PL, Moo $H$, Pang HN, Tay DK, Chia SL, et al. Intravenous versus intra-articular tranexamic acid in total knee arthroplasty: a doubleblinded randomised controlled noninferiority trial. Knee. 2016;23:152-6.

6. Wu Y, Yang T, Zeng Y, Li C, Shen B, Pei F. Clamping drainage is unnecessary after minimally invasive total knee arthroplasty in patients with tranexamic acid: a randomized, controlled trial. Medicine. 2017:96:e5804.

7. Xie J, Ma J, Kang P, Zhou Z, Shen B, Yang J, et al. Does tranexamic acid alter the risk of thromboembolism following primary total knee arthroplasty with sequential earlier anticoagulation? A large, single center, prospective cohort study of consecutive cases. Thromb Res. 2015;136:234-8.

8. May JH, Rieser GR, Williams CG, Markert RJ, Bauman RD, Lawless MW. The assessment of blood loss during Total knee arthroplasty when comparing intravenous vs Intracapsular Administration of Tranexamic Acid. J Arthroplast. 2016;31:2452-7.

9. Georgiadis AG, Muh SJ, Silverton CD, Weir RM, Laker MW. A prospective double-blind placebo controlled trial of topical tranexamic acid in total knee arthroplasty. J Arthroplast. 2013;28:78-82

10. MacGillivray RG, Tarabichi SB, Hawari MF, Raoof NT. Tranexamic acid to reduce blood loss after bilateral total knee arthroplasty: a prospective, randomized double blind study. J. Arthroplasty. 2011;26:24-8.

11. Wang H, Shen B, Zeng Y. Comparison of topical versus intravenous tranexamic acid in primary total knee arthroplasty: a meta-analysis of randomized controlled and prospective cohort trials. Knee. 2014;21:987-93.

12. Wei Z, Liu M. The effectiveness and safety of tranexamic acid in total hip or knee arthroplasty: a meta-analysis of 2720 cases. Transfusion medicine (Oxford, England). 2015;25:151-62.

13. Charoencholvanich $K$, Siriwattanasakul P. Tranexamic acid reduces blood loss and blood transfusion after TKA: a prospective randomized controlled trial. Clin Orthop Relat Res. 2011;469:2874-80.

14. Tzatzairis TK, Drosos GI, Kotsios SE, Ververidis AN, Vogiatzaki TD, Kazakos KI Intravenous vs topical tranexamic acid in Total knee arthroplasty without tourniquet application: a randomized controlled study. J Arthroplast. 2016; 31:2465-70.

15. Lee QJ, Ching WY, Wong YC. Blood sparing efficacy of oral tranexamic acid in primary Total knee arthroplasty: a randomized controlled trial. Knee surgery \& related research. 2017;29:57-62.

16. Huang Z, Ma J, Shen B, Pei F. Combination of intravenous and topical application of tranexamic acid in primary total knee arthroplasty: a prospective randomized controlled trial. J Arthroplast. 2014;29:2342-6.

17. Jain NP, Nisthane PP, Shah NA. Combined Administration of Systemic and Topical Tranexamic Acid for Total knee arthroplasty: can it be a better regimen and yet safe? A randomized controlled trial. J Arthroplast. 2016;31:542-7.

18. Seo JG, Moon YW, Park SH, Kim SM, Ko KR. The comparative efficacies of intra-articular and IV tranexamic acid for reducing blood loss during total knee arthroplasty. Knee Surg Sports Traumatol Arthrosc. 2013;21(8):1869-74.

19. Shang J, Wang H, Zheng B, Rui M, Wang Y. Combined intravenous and topical tranexamic acid versus intravenous use alone in primary total knee and hip arthroplasty: a meta-analysis of randomized controlled trials. Int J Surg. 2016;36:324-9.

20. Li JF, Li H, Zhao H, Wang J, Liu S, Song Y, Wu HF. Combined use of intravenous and topical versus intravenous tranexamic acid in primary total knee and hip arthroplasty: a meta-analysis of randomised controlled trials. J Orthop Surg Res. 2017;12(1):22.

21. Wang Z, Shen $X$. The efficacy of combined intra-articular and intravenous tranexamic acid for blood loss in primary total knee arthroplasty: a metaanalysis. Medicine. 2017;96(42)

22. Nielsen CS, Jans O, Orsnes T, Foss NB, Troelsen A, Husted H. Combined intra-articular and intravenous tranexamic acid reduces blood loss in Total knee arthroplasty: a randomized, double-blind, placebo-controlled trial. J Bone Joint Surg Am. 2016;98:835-41.

23. Lee SY, Chong S, Balasubramanian D, Na YG, Kim TK. What is the Ideal Route of Administration of Tranexamic Acid in TKA? A Randomized Controlled Trial. Clin Orthop Relat Res. 2017;475:1987-96.

24. Song EK, Seon JK, Prakash J, Seol YJ, Park YJ, Jin C. Combined administration of IV and topical tranexamic acid is not superior to either individually in primary navigated TKA. J Arthroplast. 2017;32:37-42.

25. Moher D, Liberati A, Tetzlaff J, Altman DG. Preferred reporting items for systematic reviews and meta-analyses: the PRISMA statement. Open medicine : a peer-reviewed, independent, open-access journal. 2009;3:e123-30.
26. Higgins JP, Altman DG, Gotzsche PC, Juni P, Moher D, Oxman AD, et al. The Cochrane Collaboration's tool for assessing risk of bias in randomised trials. BMJ (Clinical research ed). 2011;343:d5928.

27. Huang Z, Ma J, Pei F, Yang J, Zhou Z, Kang P, et al. Meta-analysis of temporary versus no clamping in TKA. Orthopedics. 2013;36:543-50.

28. Liu L, Yang Z, Yao J, Xu P. Effect of local injection combined intravenous drip tranexamic acid on blood loss in total knee arthroplasty. J N Sichuan Med Coll. 2015;30:611-4.

29. Gomez-Barrena E, Ortega-Andreu M, Padilla-Eguiluz NG, Perez-Chrzanowska H, Figueredo-Zalve R. Topical intra-articular compared with intravenous tranexamic acid to reduce blood loss in primary total knee replacement: a double-blind, randomized, controlled, noninferiority clinical trial. J Bone Joint Surg Am. 2014;96:1937-44.

30. Patel JN, Spanyer JM, Smith LS, Huang J, Yakkanti MR, Malkani AL. Comparison of intravenous versus topical tranexamic acid in total knee arthroplasty: a prospective randomized study. J Arthroplast. 2014;29:1528-31.

31. Alshryda S, Sarda P, Sukeik M, Nargol A, Blenkinsopp J, Mason JM. Tranexamic acid in total knee replacement: a systematic review and metaanalysis. J Bone Joint Surg. 2011;93:1577-85.

32. Alshryda S, Sukeik M, Sarda P, Blenkinsopp J, Haddad FS, Mason JM. A systematic review and meta-analysis of the topical administration of tranexamic acid in total hip and knee replacement. The bone \& joint journal. 2014;96-B:1005-15.

33. Fillingham YA, Kayupov E, Plummer DR, Moric M, Gerlinger $T L$, Della Valle CJ. The James a. Rand young Investigator's award: a randomized controlled trial of oral and intravenous tranexamic acid in Total knee arthroplasty: the same efficacy at lower cost? J Arthroplast. 2016;31:26-30.

34. Akgul T, Buget M, Salduz A, Edipoglu IS, Ekinci M, Kucukay S, et al. Efficacy of preoperative administration of single high dose intravenous tranexamic acid in reducing blood loss in total knee arthroplasty: a prospective clinical study. Acta Orthop Traumatol Turc 2016;50:429-431.

35. Pitta $M$, Zawadsky M, Verstraete $R$, Rubinstein A. Intravenous administration of tranexamic acid effectively reduces blood loss in primary total knee arthroplasty in a 610-patient consecutive case series. Transfusion. 2016;56: 466-71.

36. Ishida K, Tsumura N, Kitagawa A, Hamamura S, Fukuda K, Dogaki Y, et al. Intra-articular injection of tranexamic acid reduces not only blood loss but also knee joint swelling after total knee arthroplasty. Int Orthop. 2011;35: 1639-45.

37. Anderson DR, Dunbar M, Murnaghan J, Kahn SR, Gross P, Forsythe M. Aspirin or rivaroxaban for VTE prophylaxis after hip or knee arthroplasty. N Engl J Med. 2018;378(8):699-707.

38. Zhang XQ, Ni J, Ge WH. Combined use of intravenous and topical versus intravenous tranexamic acid in primary total joint arthroplasty: a metaanalysis of randomized controlled trials. International journal of surgery (London, England). 2017;38:15-20.

39. Zhao-Yu C, Yan G, Wei C, Yuejv L, Ying-Ze Z. Reduced blood loss after intraarticular tranexamic acid injection during total knee arthroplasty: a metaanalysis of the literature. Knee surgery, sports traumatology, arthroscopy : official journal of the ESSKA. 2014;22:3181-90.

Ready to submit your research? Choose BMC and benefit from:

- fast, convenient online submission

- thorough peer review by experienced researchers in your field

- rapid publication on acceptance

- support for research data, including large and complex data types

- gold Open Access which fosters wider collaboration and increased citations

- maximum visibility for your research: over $100 \mathrm{M}$ website views per year

At $\mathrm{BMC}$, research is always in progress.

Learn more biomedcentral.com/submissions 